$\mathrm{T}$ HE medical, social and economic problems created by a rapidly ageing population were the subject of a symposium pesented before a joint session of Sections I ( $F /$ /siology) and $J$ (Psychology) at the British Assogiation meeting at Brighton on Friday, Septeml 10,1248 .

The subje tas jntrodaced by Sir Ernest Rock Carling, $\sqrt{ }$ ho reminded his audience that the great majority of the eldorly are healthy and independent they outnumber the ailing and decrepit by more that 30 to 1 -and for them the most pressing problem is how to maintain to the end of their days the standard of living of their working life. The time has come for the elderly to revolt against the convention, based on sociological, not biological, grounds, that there is a fixed retirement-age beyond which they are unfit for further work. It is a truism that chronological age is no guide to capacity in the individual; but what we want to know is, how far the increased expectation of life in the last fifty years has extended working-capacity. Although at sixty to-day we have only a matter of months more to expect than those of that age fifty years ago, nevertheless a far greater number are reaching the sixth and seventh decades, presumably because they have been less subject in early and middle life to diseases which have come largely under control.

Ageing begins at birth, and an athlete is 'old' at thirty-five. Yet what is 'old' ? There have been few controlled researches into the causes or processes of ageing. Over the whole range of function we need the help of physiologists to measure such modification as age brings. In war they extended the functional powers of young men to a remarkable extent; by similar study they will certainly be able to suggest optimum conditions for maximum accomplishment when functions are modified or restricted by age. Just as in war combat-stress had to be allowed for, so in peace the stresses inherent in the job may be too great to be easily borne as the years pass : adaptations of work for the elderly must extend to psychological as well as physical demands.

Recent work among the derelict 'chronic sick' has shown remarkable recuperative powers among those thought to be past remedial treatment. If such efforts can restore lost powers, those powers should never have been lost; and continuance in some occupation should be, and is, a sound recommendation for the prolongation of life and happiness. Given some inducement and suitable conditions, the country can draw upon a proportion of the elderly for productive work. For the young disabled there exist workshops where, with special appliances, and adaptations of machines-and a deal of encouragement-selected jobs are accomplished.

Laziness, Sir Ernest maintained, is at the bottom of much facile acceptance of 'too old at forty, fifty, or sixty'. If the Civil servant must retire, why does not the clergyman? If the barrister ceases to practise, why not the judge?

The small percentage of the elderly whose health or social circumstances deteriorate have been in the past scurvily treated. For them the 'institution' must be replaced by small homes, graded to suit the phases of ageing and grouped to enable the residents to pass from semi-independence to full communal care without too much apparent change in surroundings. If local authorities and voluntary bodies co-operate-as they can under the National Assistance Act -it should be possible to throw off the damning inheritance of the 'workhouse' stigma that hangs about public endeavour and the 'charity' that, at least in the prejudices of some local politicians, taints private ventures. Though the proportion of old people badly needing such help may be small, the task of providing for them is enormous, for some two or three thousand homes are needed.

Dr. Marjory Warren followed with a description of her own pioneer geriatric unit at the West Middlesex County Hospital. She maintained that the tendency to lay emphasis on cure rather than care may be in part responsible for the lack of interest and industry with the so-called incurables. More than 80 per cent of the old people admitted to hospital are suffering from pathological, physiological or psychological conditions which fall under two headings, medical and social. The medical conditions are : degenerative arterial disease, degenerative heart disease, arthritis, malignant diseases, and progressive neurological diseases. The social conditions are lack of hygiene, help, food and company. A service of gerontology is needed which will integrate medical and social care. In addition to domestic and social care, such a service requires three types of accommodation : a geriatric unit based on a general hospital, a long-stay annexe for the truly irremediable, and hostels of various kinds for those reasonably fit who have no suitable home of their own. Medically, all three should be under the same supervision, because the lines between sickness and infirmity, and infirmity and health, become finer as years advance. Yet new legislation now divides the authorities for medical treatment and social care of the elderly.

Dr. Warren described the present position as chaotic and uneconomic. A very large number of remediable old people lie at home under inadequate care and no treatment, unable to get a bed in hospital. In hospitals there are elderly ambulant patients, no longer needing hospital care, for whom no hostel vacancies exist; and in hostels will be found sick old people without access to treatment.

The present writer attempted to set the old-age problem in the context of the larger problem of European population trends, which have social, economic and strategic implications for Western civilization. The population of Europe, having grown enormously - and in relation to world population-in the last three hundred years, has now reached maturity and faces relative decline. To-day it is the non-European populations that are growing fast, with declining death-rates and high birth-rates. Northwestern Europe-headed by France, once the most populous and now the most 'aged' nation-has led the process, and is destined to contract relatively to eastern Europe, and in particular to the U.S.S.R. Russia, because of late development, is relatively young; and this has a possible strategic significance. It has been estimated that, if present trends continue, another twenty or twenty-five years will see a decrease of nearly $5,000,000$ in the man-power of military age in Europe west of U.S.S.R., and an increase of more than 13,000,000 in Russia's military man-power. There is a shift in the balance of manpower from west to east.

The static, perhaps soon declining, populations of western Europe are ageing populations, and their 
working populations are ageing and declining. This means that for youngsters it is easier to start work, but harder to advance, since there are fewer opportunities at the top. The difficulty of individual advancement encourages solidarity among workers, accompanied by growing pressure in favour of early retirement-blindly regardless of the fact that the retired have to be maintained from the product of the reduced labour force. The increasing social burden substitutes group responsibility for individual or family responsibility, and the enterprising initiative of an expanding economy is replaced by a longing for the security of an ordered economy. Thus there is created the 'problem of old age'.

In the United Kingdom the present percentage of old people in the population is double what it was in 1901 , and treble what it was in 1881-just a life-time ago. It will go on increasing until, in the life-time of many now living, old people will equal or outnumber the children, and the total proportion of dependants (children and old people) to workers will increase from the present 54 per cent to 62 per cent. Only technological progress and increasing productivity will be able to keep pace with this growing social burden.

If the prospect for Britain, and Europe, appears gloomy-with our dwindling man-power and the growing predominance of other cultures-we have to remember that it was Western civilization which, in its vigorous youth, showed the world how to overcome poverty, famine and disease, and so how to release the brake upon population growth. It has yet to be proved that there is any compulsory connexion between social and animal biology, or that an ageing population means a senile body politic.

Mr. A. T. Welford described the tentative results of some experiments, in the Psychological Laboratory at Cambridge, in measuring the achievement of different age-groups at realistic and fairly complex tasks involving motor and mental skill. The first task-throwing chains at a target, first direct, then over a bar, and then with target screened and seen only in a mirror-revealed little difference in accuracy from the 'teens to the sixties until the target was screened, when accuracy fell steadily with age (and the over-thirties tended to look for the chains to throw while the youngsters kept their eyes on the mirror). In the second task the subjects were required to move a pointer on a piece of graphpaper until it corresponded with a small stationary ball on another piece alongside; if successful, the ball had to be started moving and then to be stopped in a new position, and the cycle began again. At this task there was a slightly better total achieve. ment by the under-thirties; but the older subjects' much slower, more deliberate, and also more accurate performance might in a sense be judged more efficient.

In mental skills two experiments were described which required the comprehension and organisation of data. First, in drawing conclusions from a set of logically connected statements, older people tended to treat the statements as real, and to talk about them rather than deduce from them. In the second 'mental' experiment the subjects were required to deduce, by meter-readings, the correspondence between a circuit-diagram and a box with terminals connected underneath by resistances. Here the older age-groups needed to take more readings, some more than once, which indicates their greater difficulty in organising the data and perhaps the beginnings of a loss of short-term memory. In conclusion, Mr.
Welford stressed the tentativeness of all these interpretations, but suggested that an important locus of change with age lay in the manner of organising data or comprehending a display.

Mrs. Barbara Lewis dealt with one aspect of the economic consequences of an ageing population, namely, the employment of older workers. Since such employment may become an economic necessity, it needs to be examined from both the old people's and the employers' points of view. Are old people willing to work, and is their work econornic ? Like all recent investigators Mrs. Lewis was able to confirm, from her Birmingham survey of the overseventies, the therapeutic value of continued oecupation: that women live longer than men is undoubtedly influenced by men's tendency to retire with a jolt at a fixed age, while women suffer no such sharp break. Though some men look forward to freedom to pursue hobbies and interests, there is a difference between the social and occupational groups: clerks and managers usually relish the prospect of retirement but are deterred by the certainty of a much lower standard of living, whereas manual workers frequently complain of boredom in the retirement into which they have been tempted by the smaller gap between earnings and pension.

The old people available and able for employment fall into three groups : those preferring and intending to work as long as possible; those failing or tired, who look forward to ceasing work as soon as they are financially able to retire; and those less definite about retirement, who could be swayed by a pension scheme offering greater inducements (than does the National Insurance Act, 1946) to postpone retirement or by special conditions of work if they continue.

From the employers' point of view, it is generally only when loss of efficiency and the need for trans. ference to lighter work arises that there is formal consideration of an employee's age and capacity. (On the staff side it is different, and strictly enforced retiring-ages are common, to preserve reasonable prospects of promotion.) There is no difficulty about retaining skilled craftsmen, even when pace and output fall off; but the unskilled or semi-skilled factory worker, who may, especially in heavy trades, lose efficiency with increasing years, is not so easy to retain, since alternative lighter work may be difficult or impossible to arrange. Even where old men could successfully undertake work normally done by women or boys, the trade unions' insistence on the minimum adult man's rate makes old men too expensive to use. Even if two old men could be paid only half a younger man's rate to reach the younger man's output, the costs of production will still be higher, since the administrative costs per worker have to be taken into account. On the other hand, older workers have many recommendations: they are normally more conscientious and better time.keepers, have greater respect for rules and the employer's property, and generally mind their jobs more carefully, knowing that other work will be hard to find.

As a consequence of an ageing population, industry will have to adjust itself to a labour force with a higher proportion of older workers. This may involve more mechanization and the further elimination of heavy exertion, possibly some special conditions for elderly workers, and certainly a considerable amount of research and job-analysis to reveal the types of work most suited to the employment of older workers. Mrs. Lewis concluded the symposium with the cheerful reflexion that, in encouraging old people to 
remain as long as possible in employment, the best interests of the nation and the aged coincide.

In the discussion that followed, it was clear that some lay members of the public, at least, are more interested in the causes of ageing and in the search for some partial elixir of life than in the more serious problems raised for society by a rapidly ageing population.

W. A. SANDERSON

$$
\left.35\right|^{\circ}
$$

\section{NEW BUILDING MATERIALS}

$T$ HE widespread incidence of the shortage of houses justifies even a belated account of a discussion on "Build pheriaterials with Special Reference to New Malfials", held in Section B (Chemistry) of tro Hultish Association on September 14. The full text althe four main papers read at the discussion has alleady been published*.

Speakng on "Soma Modern Trends in Building Materifls .D. F. M Zea, director of building research, Departmpit Scientific and Industrial Research, described the factors which influence both the development of new materials and new methods and their assimilation into the traditional structure of the building industry-developments which have made it essential to study building scientifically with the object of reshaping its traditions to modern needs. The potential demand for building materials is so large that the industry offers an attractive field for exploitation of newly discovered materials and a prospective outlet for industrial by-products. To be successful, a new material must be suitable in all needful respects for the purpose for which it is in. tended, and must be capable of being used without major change in existing craft processes. Large manufacturing resources and ample supplies of raw materials are essential if a new product is to become generally used. The industry can readily absorb new materials introduced on a relatively small scale, and these, if they prove to meet a real need, can be commercially successful and lead to the establish. ment of major industries, as has happened, for example, with asbestos-cement products, concrete roofing-tiles and fibre boards. Increased stress on functional requirements - thermal insulation, sound insulation and so on-leads to consideration of how the technical needs can be met by materials singly or in combination with others. This stimulates the development of new materials or new ways of using them. Changes must of necessity be slow because new materials and new techniques have to be grafted on to an established body of practice by a widely scattered labour force.

Dealing with "The Use of Aluminium Alloys in Building", Mr. E. I. Brimelow, of the Chief Scientific Adviser's Division, Ministry of Works, described the rapid growth of the aluminium industry which has brought aluminium and its alloys to the status of engineering materials in little more than a century. The strength of aluminium alloys compares favourably with that of mild steel ; the lower modulus of elasticity can be allowed for by appropriate increase in the dimensions of structural members without undue increase in weight. The relatively low melting point need cause no anxiety about the fire-resistance of loaded members; it is necessary only to provide a thicker covering for insulation and fire protection to obtain a performance comparable with that of steel.

- The Builder, 17j, 335, 365, 393, 454 (1948).
The low density of aluminium and its versatility of form fit it for use as a decorative material, as window. frames and rain-water goods, and, with due discrimination, for plumbing. It is used for spray coatings and as scaffolding. The low emissivity of clean, bright aluminium foil allows it to be used in cavity types of construction as an insulating material. Though generally resistant to corrosion, some precautions are necessary in the use and maintenance of aluminium and its alloys. Anodizing affords useful protection and gives a good surface for painting, which is recommended for rain-water goods in industrial and coastal districts. The good appearance of alum. inium window-frames can be maintained by regular washing with water or by polishing with wax. In plumbing applications, electrolytic corrosion can be avoided by appropriate choice of the associated materials and by use of insulating washers. Use of aluminium for hot- and cold-water supply installations will not be advisable until the cause of a pitting type of corrosion which occurs in some districts has been further studied. The aluminium bungalow, using aluminium in combination with foamed-concrete insulation, has made a substantial contribution to the temporary-housing programme. With some improvements, the method of construction is being extended to provide permanent houses, schools and factories. Shortage of building materials has given opportunity for trial of those new uses for aluminium which could be technically justified, and the experience so gained will be a valuable guide for the future. The advent of cheaper methods of production would increase its potentialities.

Dr. T. W. Parker, of the Building Research Station, dealt with "Light-weight Building Materials", development of which has been fostered by present demands for thermal efficiency arising from the desire to achieve economy in fuel consumption and to provide increased comfort for the occupants. Low-density blocks can be used as load-bearing materials; sheet materials form linings or cladding ; fibrous or granular materials are used as 'loose fill' or as blankets or 'bats'. Light-weight blocks, besides having a substantial insulating value, have the merit of high thermal capacity, the importance of which is often overlooked. Its influence in smoothing out variations in temperature is particularly valuable where intermittent methods of heating are installed. The greatest advance among low-density materials has been in the development of cellular concrete, which can be made in a number of different ways with a density of $20 \mathrm{lb}$. per cu. ft. upwards. Except in the aluminium bungalow, this material has not yet been used to any great extent in Great Britain, but experience in Sweden has demonstrated its potentialities. Lightweight sheets used as wall linings provide thermal insulation and offer a surface that can be quickly warmed to a comfortable temperature. Such materials must be robust enough to withstand accidental damage. They must not introduce an additional fire hazard. When circumstances preclude the use of low-density boards, the desired thermal resistance can be attained by using stronger boards fixed with an air space behind them. 'Loose fills', blankets and 'bats' form a convenient form of insulation for hollow walls and for roofs and ceilings. They must be chemically and physically stable, and should not give off noxious or combustible gases in the event of fire. They are mostly made from glass-wool, slag-wool or mineral-wool. Production of vermiculite in South Africa has stimulated interest in expanded vermiculite 